composition of the steel, and, more important, by ensuring that the steel is not put into use in an excessively hard condition.

In all, thirty-six papers were presented at the symposium and these, together with a report of the discussions, will be published in the Special Reports and Monographs series of the Institute of Metals. The symposium left a strong impression of the diversity and importance of the problems associated with internal stresses in metals, and the published account will prove to be a most valuable source of information.

\section{GROUND BLOCKS OF THE CONTINENTS AND OCEAN BOTTOMS*}

\author{
By Prof. H. CLOOS \\ Geologisch-palæontologisches Institut, Bonn
}

$\mathrm{D}$ URING the last twenty or thirty years, the scientific conceptions of the structure and development of the earth's crust have been widely influenced, if not dominated, by the Wegener theory of continental drift and by the idea of orogenetic phases dividing the structural history into short but world-wide times of movement separated by intervals of rest or of mere 'epeirogenetic' oscillations. The first theory disrupted the lateral, the second one the vertical (temporal) connexions. But within the same decades, the growth of geological knowledge of nearly all continents, combined with the results of submarine and even of geophysical investigations, pointed in another direction. They led to the conclusion that the major structural zones and units of the earth are much older than they formerly seemed, and that they indicate a long and strong continuity from the very first stages of the globe up to the present. It seems that from early geological time, the crust has been divided into polygonal fields or blocks of considerable thickness and solidity, and that this primary division formed and orientated the later movements.

My own contributions to this extensive problem date from 1910, when I first investigated the influence of old Tertiary faults upon young Tertiary folds within the Swiss Jura Mountains near Basle. Later on they dealt with the Rhinegraben, with the primary limits of the Rhenish Schiefergebirge, the Precambrian stages of important block boundaries in Norway and Sweden, with the conservative develop. ment of Silesia and the Bohemian mass, with the Harz Mountains, with North-East and South Africa, with certain areas in North America, and the Atlantic structure, the Azores and the Red Sea. Among the many important observations of other scientific investigators in different countries, Dixey's discovery of an older Nyasa fault-trough in Africa is the latest but not the least. Sonder, in his papers on Europe and Central America, laid stress upon the straight direction of certain old and persistent lineaments.

To start with the blocks, or fields, themselves, their limiting walls are to be considered as thick zones of a highly variable behaviour and history,

- Summary of the presidential address given to the annual meeting of the Geologisehe Vereinigung at Bonn on April 29, 1947, under the tifle, "Die Grundschollen der Festländer und Meere. Entwurf eines ronservativen Erdbildes"; a detailed account is being published in the Geologische Rundschau, Stuttgart, No. 2 (1947). and should be called 'geofractures' or 'geosutures', analogous to the similar terms 'geosynclines' and 'geanticlines'.

The critical features of these ancient and deep units and of their limiting zones are: (1) stratigraphical traces of tectonic movements in earlier geological times; (2) the connexion with plutonio and volcanic activity in early and recent times, etc. ; (3) their relations to deep-seated earthquakes of linear arrangement (down to 500 or even $700 \mathrm{~km}$.) ; (4) the length of the limiting zones (up to several thousand kilometres); (5) the size of the blocks, which varies between 500 and 1,200 or even 1,500 $\mathrm{km}$. in diameter. My experiments and the known physical and technical observations show that there exists a geometrical relationship between the mutual distances of the dissecting joints and the thickness of the dissected sheet.

The crust pattern formed by these ancient geosutures displays several astonishing regularities. Within the three northern continents, blocks of north-south trend limited by meridional sutures are predominant. In North America, eight such fields can be counted; in Europe, eight north of the young mountain ranges in the south; in Asia, a few more. In the Mediterranean girdle, east-west zones prevail. On the Atlantic bottom, longitudinal zones of oblique directions are well known. Their analogy and connexion with terrestrial zones lead to the conclusion that they are the submarine representations of the ancient continental lines. It seems that many continental slopes belong to the deepest, oldest and most important block boundaries, an opinion already included in the well-known theory of the 'permanence' of the continents and oceans.

As areas of different horizontal and vertical dis. placement, the great thick permanent ground blocks influence the sedimentation on their upper surface, and also the magmatic cycles on their under surface within their interior and along their limiting walls. Being older than most of the other tectonic features of the globe, they influence the preparation, the origin and the development of the folded mountain ranges as well. Roughly speaking, within the two main thermodynamic girdles, each block has its own folded range. The structural relations between the younger folding and the older configuration of the respective blocks vary broadly according to the direction of the folding movement relative to the pre-shaped contour of the field. Longitudinal ranges, for example, are usually straight (Urals). Transverse ranges are suspended between the marginal sutures either as garlands or festoons, or in a sigmoidal manner or both (Füllhorn of the Alps). Thus attempts to unite the different folded arcs into uniform and endless 'slings' can be replaced by their individual adaptation to pre-existing units of the crust.

In certain examples, the deformation of a broad superficial area (like the Rocky Mountains in the United States or the corresponding area in Western Europe) can be derived from a more or less homogeneous deformation (for example, a simple torsional shear) of the supporting block. In a recent experi. ment I succeeded in imitating the structure of the Rocky Mountains. A sheet of liquid clay lies on a square wire net. Films of thin paper impregnated with water lie closely on the smoothed surface of the clay. A minute torsion of the wire net suffices to produce the Rocky Mountain uplifts with their typical details and their oblique arrangement. The mutual distances of the individual uplifts are pro. 
portional to the number of sheets of paper applied, that is, to the thickness of the sheet of sediments. If the cover of paper is omitted and the other conditions are unaltered, the experiment produces the faults of the adjacent Basin and Ranges field. This variation corresponds exactly to the natural model.

Consequently, the tectonic deformations of the crust and the main features of its surface history can be more easily and better understood if we do not connect the visible structures directly with the supposed underground forces (subcrustal currents, convection as an effect of thermodynamic alterations, etc.). It is simpler to introduce an anisotropic and heterogeneous aggregate of pre-formed units which act as supports for the superficial material and as points of attack, as levers, and as instruments of transportation for the underground causal forces.

\section{PRESERVATION OF THE KAURI IN NEW ZEALAND}

$\mathrm{I}_{z}^{\mathrm{N}}$ a series of short newspaper articles in New Zealand, Prof. V. J. Chapman (professor of botany at Auckland University College) gives the conclusions he has reached on a problem of much interest to botanists and tree-lovers the world over, namely, the preservation of that remarkable tree, the kauri (Agathis australis Salisb.).

The only surviving extensive block of natural forest carrying big kauri is Waipoua Forest, covering some 30,000 acres and in the care of the State Forest Service. Here the kauri, including trees of outstanding size, occurs scattered throughout, mainly in groups. It is claimed that this tree may exceed even the Sequoias in timber content, owing largely to the remarkable way in which the trunk holds to the cylindrical form instead of tapering considerably towards the crown. Younger trees and saplings are to be found, but only in limited numbers. Experimental sowings or plantings have not always been successful, and though the N.Z. Forest Service is now more or less prepared to guarantee regeneration of this species, its critics do not yet appear convinced -a matter which it should be easy to settle on the spot.

Two main questions have arisen: What steps should be taken to ensure the protestion of an adequate number of the existing big trees and the perpetuation of the species; and if for this purpose areas are excluded from green fellings, should dead and dying trees be utilized before they decay ? It is alleged that the Forest Service has not hitherto publicly guaranteed complete protection from interference for any part of the forest, not even for the roadside strip, and that when felling for timber, usually takes all trees down to $30 \mathrm{in}$. in diameter and all dead and unhealthy trees fit for milling.

In Prof. Chapman's party, when he made the inspection of the forest on which his articles are based, the botanical and amenity interests were strongly represented, but unfortunately there does not appear to have been an experienced forester with them. To get the disinterested forestry point of view, he referred the matter as just another instance of a general problem to the sylviculturist of the Indian Forest Research Institute, and to the present reviewer, who has for many years campaigned among his colleagues and others for the preservation of outstanding trees and adequate samples of the forest types of which they form part: neither knew that Prof. Chapman intended publication. Meanwhile, the New Zealand Institute of Foresters has published a well-reasoned account of its view $(J . N . Z$. Inst. Forest., 5, No. 3, 173-175 ; 1946).

There seems to be agreement that a portion or portions of the forest should be excluded from fellings with suitable safeguards against change of policy, as has already been done by the N.Z. Forest Service in a working plan already six years old. All living trees on a fairly wide strip on either side of the State highway should be, and indeed are, to be kept untouched in this way, for in New Zealand, as in Great Britain, the truth is that appreciative as a large section of the general public may be of woodland amenities and big trees, it rarely goes far from the road. A certain number of exceptional trees should obviously also be specially protected, and access provided : this also has already been decided on.

Scientific interests, including those of forestry itself, call for the preservation of a further compact block of forest (not a narrow strip), which would be excluded from ordinary management. One or two areas of about 250-500 acres each might be suggested, and there is a good case in favour of leaving in them even dead trees standing or fallen, as it is very likely indeed that some part of the fauna is dependent on the dead and decaying wood for its existence and survival. We understand one such area has already been set aside for the purpose.

Over the rest of the forest, normal management for timber production can be permitted. It is remarkable how fully the amenities of a forest area can be maintained with such management where it is the settled policy so to maintain the:s : the New Forest in England provides an example, thanks to the care of the deputy surveyor, for it is almost incredible that more than two dozen sawmills were working there throughout most of the war-years with so little consequent loss to the amenities or even change in appearance. Prof. Chapman urges that in the managed portion, kauri should be retained as the principal species, just as in Britain it has been decided in certain forests that broad-leaved trees should not be replaced by conifers : we believe this to be desirable and that the State Forest Service is willing to agree. But just how that will be $\operatorname{don} \theta$ is not yet known, for on the information before us the kauri is a baffling tree, and a good deal more systematic research work will have to be done before it can be regenerated to order. Recorded information makes it clear that rather special conditions are required for the successful germination of the seed and establishment of the resultant plant; it is, however, not yet adequately known what those conditions are, though, as with many other trees, a primary requirement appears to be exposure of the mineral soil from its excessive covering of humus. The grouped occurrence, though by no means a unique feature in forest vegetation, has repeatedly been described, and studies are needed on soil and vegetational differences inside the groups and outside : the kauri, of course, itself influences the soil in which it grows and on which it showers its dead leaves and twigs. There is also a question of fungal association with the roots, which may incidentally play some part in the difficulties experienced in the nursery with this species. The importance of greater concentration on this research is underlined by the recommendation that until it is well under way only dead timber should be removed. 